Review

\title{
Significance of Infectious Agents in Colorectal Cancer Development
}

\author{
Vlado Antonic ${ }^{1,2,3 凶}$, Alexander Stojadinovic ${ }^{1,3,4,5,6}$, Kent E. Kester ${ }^{1,6,7}$, Peter J Weina ${ }^{6,7}$, Björn LDM Brücher ${ }^{8,9}$, \\ Mladjan Protic 5,10,11,12, Itzhak Avital6,8, Mina Izadjoo 1,2,3,6 \\ 1. Combat Wound Initiative Program, Bethesda, MD, USA. \\ 2. Diagnostics and Translational Research Center, Gaithersburg, MD, USA. \\ 3. Henry M. Jackson Foundation for the Advancement of Military Medicine, Bethesda, MD, USA. \\ 4. Department of Surgery, Walter Reed National Military Medical Center, Bethesda, MD, USA. \\ 5. United States Military Cancer Institute, Bethesda, MD, USA. \\ 6. Uniformed Services University of the Health Sciences, Bethesda, MD, USA. \\ 7. Walter Reed Army Institute of Research, Silver Spring, MD, USA. \\ 8. Bon Secours Cancer Institute, Richmond, VA, USA. \\ 9. International Consortium of Research Excellence of the Theodor-Billroth-Academy®. \\ 10. INCORE, International Consortium of Research Excellence of the Theodor-Billroth-Academy, Munich, Germany. \\ 11. Clinic of Abdominal, Endocrine, and Transplantation Surgery, Clinical Center of Vojvodina, Novi Sad, Serbia. \\ 12. University of Novi Sad - Medical Faculty, Novi Sad, Serbia.
}

Corresponding author: Vlado Antonic, Diagnostics and Translational Research Center, 401 Professional Drive, Gaithersburg, MD. Email:vantonic@dtrc-hjfresearch.org. Phone: +1 3017688750 FAX: +1 2408334940.

( ) Ivyspring International Publisher. This is an open-access article distributed under the terms of the Creative Commons License (http://creativecommons.org/ licenses/by-nc-nd/3.0/). Reproduction is permitted for personal, noncommercial use, provided that the article is in whole, unmodified, and properly cited.

Received: 2013.0I.07; Accepted: 2013.02.10; Published: 2013.03.15

\begin{abstract}
Colorectal cancer (CRC) is a major burden to healthcare systems worldwide accounting for approximately one million of new cancer cases worldwide. Even though, CRC mortality has decreased over the last 20 years, it remains the third most common cause of cancer-related mortality, accounting for approximately 600,000 deaths in 2008 worldwide. A multitude of risk factors have been linked to CRC, including hereditary factors, environmental factors and inflammatory syndromes affecting the gastrointestinal tract. Recently, various pathogens were added to the growing list of risk factors for a number of common epithelial cancers, but despite the multitude of correlative studies, only suggestions remain about the possible relationship between selected viruses and bacteria of interest and the CRC risk. United States military service members are exposed to various risk factors impacting the incidence of cancer development. These exposures are often different from that of many sectors of the civilian population. Thereby, cancer risk identification, screening and early detection are imperative for both the military health care beneficiaries and the population as a whole. In this review, we will focus on several pathogens and their potential roles in development of CRC, highlighting the clinical trials evaluating this correlation and provide our personal opinion about the importance of risk reduction, health promotion and disease prevention for military health care beneficiaries.
\end{abstract}

Key words: infection, bacteria, virus, infectious agent, colon cancer, colorectal cancer, cancer risk.

\section{Introduction}

Cancer is defined as uncontrolled, malignant cell proliferation caused by accumulated genetic or epigenetic mutations ["two hit" /"multi-hit" model (1)].
Colorectal cancer is the third most common cause of cancer-related death in woman and the fourth leading cause of cancer mortality in males. Over 140,000 new 
cases of CRC is estimated for the U.S. in 2012 with disease-specific mortality of up to 60,000 reported in 2011. Colorectal cancer scan be classified as inherited (due to genetic instability), inflammatory (due to presence of chronic inflammation of gastrointestinal tract, e.g., Crohn's disease) or sporadic, which accounts for more than $80 \%$ of all CRC.

The latter group, sporadic CRC, is the focus of tremendous epidemiological research efforts with the goal to determine potential causative and risk associated factors for the disease. There are some large-scale, population-based studies that have reported several risk factors for CRC development; however, these studies are difficult to recreate within the laboratory. Complexity of carcinogenesis is the main reason for the challenges of epidemiological identification of causative factors and the subsequent laboratory-based testing of their direct involvement in malignancy. Thus far, these studies have pointed to high-fat diet, living in Western countries (which can be related to the diet of the western civilizations, diet higher in red meat and fats) and obesity as risk factors for CRC. On the other hand, vitamin D, high fiber diet and fish intake are associated with decreased risk of CRC. The long list of cancer risk factors continues to evolve, and in the past few decades has expanded to include infectious agents. A number of infectious agents are considered to be cancer risk factor due to the hypothesis-generating and supportive evidence accumulated to date.

It has been estimated that one fifth of all cancer is caused by some infectious agent(s). The role of viruses in human cancer, especially small DNA viruses (e.g., polyomaviruses, papillomaviruses and Epstein-Barr virus) including Merkel cell carcinoma, cervical cancer, Burkitt's lymphoma, Hodgkin's lymphoma, nasopharyngeal carcinoma is well recognized. In the last couple of decades, there has been accumulating evidence in the literature about the link between bacterial infection and cancer, particularly the association between Helicobacter pylori and gastric adenocarcinoma (2). Association of medullablastoma and brucellosis was first discovered in the laboratory of one of the authors in this review paper (3). In the case of CRC, the most recent list of acknowledged risk factors still does not include infectious agents, despite the current trend in the literature that supports this association. It is reported that viruses and bacteria can cause CRC through direct mutagenesis, secretion of mutagenic products and/or prolonged infection and accompanying inflammation that leads to increased epithelial cell proliferation. This increased cell proliferation, on the other hand, has the potential to preferentially select cancerogenic clones. Data available that addresses specific mechanisms remains limited and well-designed clinical trials with large patient populations to provide adequate statistical power are needed in order to adequately evaluate this hypothesis.

The incidence rate of CRC in the military service members differs from the general population because of varying exposure to risk factors predisposing to the disease. Therefore, caution is advised when translating epidemiological data from population on the whole to CRC incidence and prevalence rates amongst military service members. Very limited data exists comparing incidence rates of cancer overall in service members to civilians. Those data that do exist are derived from studies reporting that the incidence of CRC may be lower in the military than in the general population. One hypothesis is that these differences may reflect varying degree of compliance with CRC screening amongst the populations studied, emphasizing the need for increased CRC screening in the military health system (4). Other probable reasons that may account for the observed difference in CRC incidence between the two populations are that service members comprise a younger patient population, generally more physically fit due to fitness requirements, with better access to the healthcare; however, data for veterans and retired service members may be incomplete due to their transfer of care to various civilian hospitals following completion of military service. The Center for Disease Control and Prevention reported that early detection of CRC decreases mortality, emphasizing that five year survival is 90 percent when CRC is detected early when node-negative and non-metastatic; unfortunately, only $40 \%$ of cases are identified at such an early stage (5).

The purpose of this review is to summarize and critically assess the current level of evidence that either supports or contradicts the hypothesis that certain bacteria and viruses contribute to the development of CRC. Herein, we specifically focus on clinical research completed to date, and the relevance of this hypothesis to the military health system.

\section{Do bacteria cause colorectal cancer?}

The human gastrointestinal tract is colonized by more than 100 trillion bacteria. This complex microbial community carries a rich and diverse microbial genome, the microbiome, with a tremendous metabolic potential to influence intestinal homeostasis and function. The colon is the part of the gastrointestinal tract that accounts for the majority of these bacteria. Specifically, the colon is populated with $\sim 10^{14}$ bacteria (6). There was a generally accepted and well estab- 
lished opinion amongst biologists and medical scientists, that this bacterial "burden" is not harmful, on the contrary, very beneficial.

Resident colonic bacteria in fact provide nutrients to the colonic mucosa; they play a major role in the development and function of the mucosal immune system, prevent colonization with pathogenic bacteria, and help maintain the physiological microenvironment. Studies of bacterial species present under normal conditions and epidemiological studies of gastrointestinal cancers led researchers to propose a potential causal link between certain pathogenic bacteria and human CRC. One such contributory finding is the observed anatomic predisposition for the development of cancer, which can be correlated with the presence and quantity of bacteria; hence, the risk of developing CRC is 12-fold higher than that of other parts of the gastrointestinal tract (small intestine). This finding corresponds to a significant differential in number of bacteria per $\mathrm{ml}$ populating these two anatomic regions (1012 and $10^{2}$ in the colon and small intestine, respectively) (6). Animal models have expanded our understanding of the gastrointestinal microbiome and its importance in the development of CRC showing much smaller incidence of CRC in germ-free, genetically susceptible animals for CRC than in those animals living in germ-present conditions; in addition some knock-out strains (i.e. TCR $\beta /$ p53 (7), IL-10 (8), Gpx1/Gpx2 (9), Gai2 (10), Smad3 (11), Muc2 (12), Tgf $\beta 1 / \operatorname{Rag} 2$ (13), IL-2/ $\beta 2 \mathrm{~m}$ (14)) have shown similar findings. The availability of genetically-engineered rodent models has greatly facilitated the etiologic study of CRC. However, despite the enormous efforts to explore the causal link between pathogenic bacteria and CRC, epidemiological data has not been easily reproduced within the laboratory, leaving room for various theories about bacterial involvement in colorectal carcinogenesis. However, recently it also had been sown, that paradoxical changes in nucleic acid damage could be observed in mice: infection-induced colitis by Helicobacter hepaticus revealed cell stress response with DNA-damage - a model which supports an inflammation-mediated carcinogenesis cascade (15).

Researchers have been able to identify some mechanisms by which bacteria could affect normal or susceptible cells and push them toward a malignant phenotype. An interesting experimental model for the involvement of the bacterial community in CRC development was proposed by Tjalsma et al. According to this model, named "driver-passenger" based on next generation genomic sequencing each of the stages of CRC development has a specific pathogen(s) associated with it (6). As the CRC progress, bacterial populations associated with each cancer stage change with the natural history of disease, providing the necessary stimuli that further encourage cancer development and progression.

In last couple of decades, a multitude of clinical trials have been presented, indicating several infectious agents as potential contributors to CRC development. Even though, there is substantial epidemiological evidence pointing to an association of the gut microbiome with CRC, the composition of gut microbiota in CRC patients has yet to be adequately described. In 2012, researchers used a pyrosequencing approach to detect fecal bacterial diversity in 46 CRC cases and 56 healthy volunteers by profiling the V3 region of the $16 \mathrm{~S}$ ribosomal RNA gene (16). Amongst them, Bacteroidesfragilis, Enterococcus, Escherichia/Shigella, Klebsiella, Streptococcus and Peptostreptococcusspp .were significantly more abundant in the gut microbiota of CRC patients than in unaffected cases (16).

As a result of a large body of data derived from numerous clinical and laboratory trials, several bacteria have been identified and implicated in the development of CRC. These include: [1] Streptococcus bovis, [2] Helicobacter pylori, [3] Escherichia coli, [4] Klebsiella pneumoniae, and more recently, [5] Fusobacterium. We will focus on the clinical studies evaluating the importance of these specific bacterial - CRC associations and laboratory studies that provided mechanistic support for these potentially etiological relationships,.

\section{Streptococcus bovis (biotype 1) /Streptococcus galloliticus}

Streptococus bovis is one of the first bacteria suspected to be associated with CRC. S. bovis is a commensal bacterium, an opportunistic pathogen carried by about $16 \%$ of the general population. The initial reports about its association with CRC date from the mid-1970's (17). In later nomenclature, its name was changed from S. bovis (biotype 1) into S. galloliticus (18) based on its genetics and correlation with CRC. After meta-analysis of 11 studies linking S. bovis biotype 1 , infective endocarditis (IE), and colorectal adenomas/carcinomas, the authors suggested separation of S. galloliticus subspecies galloliticus from S.bovis, due to its strong association with CRC (pooled odds ratio [OR], 7.26; 95\% confidence interval [CI], 3.94-13.36) and IE (pooled OR, 16.61; 95\% CI, 8.85-31.16), compared with the significantly increased, albeit lower OR of $S$. bovis biotype II-infected patients. Notably, CRC occurred more often among patients with $S$. bovis IE than among patients with $S$. bovis infection at other sites (pooled OR, 3.72; 95\% CI, 2.03-6.81). 
Since the mid-70's, several clinical studies evaluated the association of S.bovis/galloliticus with CRC and demonstrated different, if not contradictory results. The first indication that $S$. bovis could play an important role in CRC came from the epidemiological studies of patient populations with endocarditis and S.bovis/galloliticus bacteremia. It has been found that $25-80 \%$ patients with bacteremia and $18-62 \%$ patients with infective endocarditis have underlying colorectal tumors (19-23).

Retrospective analysis of a microbiology database with special focus on underlying gastrointestinal disease or other major comorbidities was performed on 46 patients (24). Colonic neoplasms (adenocarcinoma in three and adenomatous polyps in three) were found in 6 of 10 adult patients in whom colonoscopic evaluation was performed. Gold conducted a trial of45 patients with S. bovis/galloliticus and an associated was identified between infection with these pathogens and with both colonic neoplasia $(39 \%$ of adults underwent colonoscopic examinations) and extra-colonic malignancy.

A serological, Enzyme-Linked Immunosorbent Assay (ELISA)-based clinical study evaluated the presence of IgG for S. bovis, but did not show any statistically significant association between the presence of this bacterium and CRC. However, this was a small study of 16 cases and 16 matched case-controls which may have been under powered (25). Evaluation of the presence of S.bovis/gallactoliticus in the feces of CRC patients and their matched controls showed no difference between these two populations (26-28). These findings were confirmed in an independent study (29). It has to be pointed out that these studies were all of small sample size, and utilized bacterial culturing techniques with well recognized limitations, as the indicator of bacterial presence.

Utilizing modern, molecular biology techniques, researchers have showed the opposite results (30) highlighting the importance of this bacterial-CRC association. These same authors evaluated the expression patterns of messenger RNA (mRNA) for pro-inflammatory genes, NF-kB and IL-8, and concluded that $S$. bovis/gallactoliticus potentially promote colorectal neoplasia by utilizing certain inflammatory, anti-apoptotic, and pro-angiogenic factors (31). Boleij et al. (2012) used a multiplex approach for the serological detection of $S$. bovis in order to precisely detect infection and its association with CRC. They evaluated the presence of antibodies against 4 pilus proteins and showed dominance of one antibody to one of four pilus proteins rarely present in both Dutch and American populations (32).

When study conducted on larger patient popu- lations, studies have shown strong correlation between S.bovis/galloliticus infections and CRC. A case-controlled study (33) showed that the prevalence of CRC was significantly higher in patients with SGG bacteremia than in 196 control patients $(70 \%$ vs. $32 \%$; odds ratio [OR], 5.1; 95\% confidence interval [CI], 3.0-8.6). This difference was not significant when comparing non-advanced adenomas (19\% vs. $12 \%)$. Importantly, significant differences in advanced adenomas (40\% vs. $16 \%$; OR, 3.5; 95\% CI, 2.0-6.1) and invasive carcinomas ( $12 \%$ vs. $5 \%$; OR, $2.9 ; 95 \% \mathrm{CI}$, 1.2-6.9) were reported.

In a laboratory setting, particularly for in vitro studies, much more consistent results have been obtained to provide confirmatory clues for the S.bovis/galloliticus - CRC association. These in vitro studies evaluated the ability of S.bovis/galloliticus to induce (pre)cancerous lesions, its ability to survive in the micro-environmental niche of the cancerous tissue (34), and its ability to form biofilms in the collagen matrices seen in vivo at damaged heart valves and (pre)cancerous sites with a displaced epithelium (35). S.bovis/galloliticus were grown in spent medium of malignant colonocytes to simulate the altered metabolic conditions within the CRC microenvironment. In vitro simulations indicated that S.bovis/galloliticus had a significant growth advantage in these spent media, which was not observed for other commensal intestinal bacteria (34). In a second study, Boleij et al. showed that S.bovis/galloliticushas low attachment capability and has advanced capabilities to form biofilm in collagen rich matrices. Interestingly, the bacterium does not enter epithelial cells, but it does possess the ability to 'para-cellularly' cross epithelium without an IL- 8 and IL-1 $\beta$ response (35). All these data indicate that S.bovis/galloliticus have a set of virulence factors that allow it to trigger and/or promote CRC.

\section{Helicobacter pylori}

Helicobacter pylori is classified as a class I carcinogen by the International Agency for Research in Cancer (36) due to the strong correlation between $H$. pylori infection and gastric cancer. H. pylori infections usually start at a young age and can last for prolonged periods of time, up to years and decades (37). H. pylori a gram negative rod, is well adapted for life within the human stomach. It invades through a $\mathrm{pH}$ neutral niche between the mucus layer of the stomach and the gastric epithelium; it further has a set of adaptations which allows it to survive and modify innate immune responses (38-39). Interestingly, $H$. pylori does not invade tissues. Also, it does not enter epithelial cells nor does it penetrate the basal membrane; however, $H$. pylori does cause prolonged inflammation (40) 
which is one of its proposed mechanisms for the development of neoplastic changes. Other mechanisms involve production of molecules that either have direct effect on epithelial cells (ammonia, cytotoxin-associated gene-A-positive $\left(\mathrm{CagA}^{+}\right)$or exert an indirect effect through stimulation of macrophage production of nitrates and free radicals.

Several studies evaluating the potential association of CRC and H.pylori infection have been done. In these studies, various methods for the detection of $H$. pylori infection have been utilized [serology, polymerase chain reaction (PCR), histology, C14-Urea breath test]. These various studies have led to different, at times opposite conclusions, even in cases where the same method of $H$. pylori detection was utilized.

Three studies (41-42), (43) evaluated if a difference in the bacterium, $\mathrm{CagA}^{+} H$.pylori versus $\mathrm{CagA}^{-} H$. pylori, has any effect on CRC and associated lymph node metastasis. CagA ${ }^{+} H$. pylori have been reported to induce greater degree of inflammation than the CagA-strain, which leads to chronic atrophic gastritis. Two of these studies had positive results, and one led to a negative conclusion. A prospective study of male smokers 50-69 years old did not show any statistically significant differences or neoplasia correlation in the serum from 118 cases and 236 matched controls. They stratified data per strain and per location of the tumor. On the basis of these data, $H$. pylori carriage does not appear to be an important risk factor for CRC. In this nested case-control study of older Finnish male smokers, however, H.pylori seropositivity was not significantly associated with overall or sub-site-specific risk incident CRC. These findings correlate with two other reported studies (44-45) and are contrary to the findings from two other studies (46-47). These contradictory results could be due to differences in study design and number of participants.

A large cross sectional study of 2,195 patients showed the prevalence of colorectal adenoma and advanced adenoma was significantly higher in the $H$. pylori $(+)$ than in the $H$. pylori $(-)$ group $(25.3 \%$ vs. $20.1 \%, p=0.004$; and $6.1 \%$ vs. $2.9 \%, p<0.001$, respectively) and showed that $H$ pylori presence is a significant associated risk factor, but with limited importance (48). In Germany, one large study of 1,712 incident CRC cases and 1,669 controls (49), and another study of 384 incident cancer patients and 467 matched control subjects, (50) measured serum antibodies to H. pylori and CagA. Both studies showed that this bacterium may be associated with small but clinically relevant risk for the development of CRC. Interestingly, Zumkeller et al. showed that the IL-1 pro-inflammatory polymorphism in the population decreased the risk of CRC development. On contrary, group of 344 patents, 118 cases and 236 matched controls were assayed for both $H$. pylori whole cell and $H$. pylori CagA antibodies (51). In total, 258 (73\%) and 212 $(60 \%)$ subjects expressed whole cell and CagA antibodies, respectively. $H$. pylori seropositivity, defined as one or both antibody assays positive, was present in $273(77 \%)$ subjects. None of these values are statistically different, and the authors concluded that carriage of $H$. pylori is not a risk factor for CRC. From initially enrolled 1794 patients in two trials (52) cohort of 685 patients, who had serum samples available, have been followed for three years and screened for CRC. 239 patients were infected with H. pylori and had significantly higher serum levels of gastrin. In fully adjusted models, gastrin levels were not associated with incident adenoma development (risk ratio [RR], 1.10; 95\% confidence interval [CI], 0.78-1.54) or advanced adenoma formation (RR, 0.82; 95\% CI, 0.33-2.03). A positive $H$. pylori serology was associated with a decreased risk for adenoma formation (RR, 0.76; 95\% CI, 0.60-0.96) suggesting that no correlation can be made between gastrin levels, $H$. pylori infection and CRC.

Three meta-analyses have been reported evaluating 11, 13 and 14 human clinical trials, respectively (53-55). Zumkeller et al. reported negative results indicating the possibility of bias in some of the analyzed individual studies. Two other studies confirmed the significantly increased risk of CRC in patients with $H$. pylori infection. More case controlled studies with larger patient cohorts are needed in order to allow definite conclusions about the apparent strong relations reported in some studies between $H$. pylori infection and CRC. The reported increase in H. pylori infections observed in young military service members (56-58) might have a significant impact on the long term survival of this patient population in the forthcoming decades.

\section{Other bacteria}

Klebsiella pneumoniae is a Gram-negative, non-motile, encapsulated, lactose fermenting, facultative anaerobic, rod shaped bacterium found in the normal flora of the mouth, skin, and intestines (59). It is most commonly associated with pneumonia and is a common cause of infections in the urinary tract, lower biliary tract, and surgical wound sites. Pyogenic liver abscess (PLA) is caused by bacteria and depending on the geographical data, most commonly isolated bacteria from pyogenic liver abscesses are E.coli for the western countries and K. pneumoniae for the eastern populations. Since the 1990s, there are 
more reports showing that $K$. pneumoniae is the most common cause of PLA within western countries as well (60). There are a number of case reports showing a positive correlation between PLA caused by $K$. pneumoniae and CRC. In one meta-analysis, 30 case reports were identified and analyzed along with two case-controlled studies (61). Researchers found strong correlation between $K$. pneumonia-caused PLA and CRC and they reported isolation of these bacteria from $50 \%$ of this patient population. A case controlled study comparing CRC occurrence in patients with cryptogenic PLA was conducted on 230 patients (62). Of those, 81 patients were categorized as cryptogenic PLA and 37 of them underwent colonoscopy. Seventy seven percent of the patients with CRC, laterally spreading tumor or colon ulcers were tested positive for $\mathrm{K}$. pneumonia in the abscess samples. A retrospective study was conducted on 2,294 patients (63) of which 1,194 (52\%) had K. pneumoniae infection. During a 10-yearfollow-up period, 54 (2.3\%) patients were diagnosed with CRC, corresponding to an overall incidence rate of 669.1 (95\% confidence interval [CI], 490.7-847.6) per 100,000 person-years. The adjusted hazard ratio of CRC was 2.68 times greater for patients with $K$. pneumonia PLA than for those with non-K. pneumonia PLA (95\% CI $=1.40-5.11)$. There is very limited mechanistic data to support these findings, even though there is an increasing body of evidence about the positive correlation between $K$. pneumonie PLA and CRC.

Fusobacterium spp. recently made its way to the prestigious journal, Nature Reviews Gastroenterology and Hepatology after several publications correlated its presence with CRC. Fusobacterium is the genus of anaerobic, Gram-negative bacteria rod-shaped bacilli with pointed ends. Strains of Fusobacterium contribute to several human diseases, including periodontal diseases, Lemierre's syndrome, and topical skin ulcers. Although older resources have indicated that Fusobacterium occurs commonly in the human oropharynx, the current consensus is that Fusobacterium should always be treated as a pathogen. In 2011, researchers discovered that this bacteria flourishes in colon cancer cells, and is often also associated with ulcerative colitis. However, researchers have not determined if the organism actually causes these diseases or if it simply expands in the environment that these diseases create. In contrast to Bacteroides spp., Fusobacteria have a potent lipopolysaccharide. Two studies used the same methodology to detect Fusobacterium spp in CRC. One group used DNA markers to detect the presence of bacteria (64) while the second group used RNA sequencing (65) to detect bacteria. Both groups came to the same conclu- sion: Fusobacterium spp. (64) and Fusobacterium nucleatum (65) are strongly correlated with CRC. The latter group showed its importance in metastasis of CRC to lymph nodes.

\section{Viruses and colorectal cancer}

Since the discovery of Rous sarcoma virus in 1911, numerous viruses were detected and proven to cause some type of cancer. A monumental breakthrough was made in the mid-1960s with the discovery of Epstein-Bar Virus and its correlation with Burkitt's lymphoma. Since then, numerous studies have focused on the link between viruses and human carcinomas and the mechanisms of cell transformation caused by viruses. A causal link between viruses and human cancers was established for nasopharyngeal carcinoma, post-transplant lymphomas, and some Hodgkin's lymphomas, liver cancers, cervical cancer, and squamous cell carcinoma.

Several mechanistic studies provide evidence for viral-induced transformation and malignancy. Along with the evaluation of mechanisms, viruses eventually became a very useful 'dissecting tool' for understanding cell cycle and protein interactions. Despite many differences between human oncogenic viruses, there is at least one common feature to efficiently transform the infected cells: targeting important cellular signaling pathways through virus-encoded oncoproteins. There are many cellular pathways that regulate cell-fate, with numerous opportunities for tumor viruses to manipulate these pathways in order to promote virus-mediated cancers. These viruses are capable of deregulating tumor suppressor genes; inducing chromatin remodeling and regulating cellular transcription; modulating the inflammatory response and modulating COX-2 in regulating this response; targeting tumor suppressors (i.e. p53 and Rb), various signaling pathways like Notch, JNK, and the cyclin-CDK pathway (66-67).

Several viruses were suggested to be the risk factors for CRC. Among them, John Cunningham virus (JC virus), BK virus, Human Cytomegalovirus (CMV), Human papilloma viruses (HPV: particularly type 16 and 18) have the largest number of reports. However, there are a smaller number of studies evaluating the role of viruses in CRC compared to other risk factors. In addition, these studies usually report contradictory results, have small patient populations or sample numbers, and as such, no definite conclusions have been made between the particular virus of interest and CRC.

\section{Human polyoma viruses (JC virus)}

$\mathrm{JC}$ virus is the member of polyomaviruses, small 
double stranded linear DNA viruses. JC virus is present in $80 \%$ of population. It is present in the kidneys where it remains latent in healthy individuals. In the immune compromised hosts (e.g. organ transplantation recipient, or HIV seropositivity) it becomes reactivated. Its genome encodes for the large T-antigen protein that can interact with p53 and pRB (tumor suppressor proteins) as well as other key signaling pathways.

The first reports suggesting that JC virus can play role in human CRC date from 1999 (68). Shortly after this, more studies have reported an association of JC viral infection with CRC. Casini et al. reported that 16 out of 18 patients $(88.9 \%)$ have been positive for the presence of JCV DNA, assessed with three techniques, PCR, Northern blot and in situ hybridization, within the primary tumor mass and peri-tumoral tissue (69). A study of 27 patients, found 22 to be JVC positive. Expression of the viral oncogenic early protein, $\mathrm{T}$-antigen, and the late auxiliary protein, Agnoprotein, was observed in $>50 \%$ of the samples, also showing that JCV can interact with $\beta$-catenin, which in turn dysregulatesthe Wnt pathway and finally the c-myc promoter (70). T-antigen has been reported to cause chromosomal instability (71) in vitro and JCV T-Ag DNA sequences were found in $77 \%$ of CRCs studied; and $56 \%$ of these cancers (or $43 \%$ of the total) expressed T-Ag by IHC. A study from Taiwan, which was conducted on formalin-fixed, paraffin-embedded tissues from 22 colon cancer patients, identified genomic DNA in $86.4 \%(19 / 22)$ of the CRC tissue samples. This study also identified expression of viral early protein, but not structural capsid protein, in the examined colon cancer tissues (72). When the upper and lower parts of the gastrointestinal tract (small intestine and colon) are studied and compared for the presence of the JC viral DNA, researchers found $75.8 \%$ of immunocompetent patients $(70.6 \%$ of upper GI and $81.2 \%$ of colonic samples) to be carriers, leading the investigators to hypothesize that the gastrointestinal tract acts as a reservoir of JC viruses $(68,73)$.

Immunohistochemical staining was performed on 74 paraffin-embedded adenomatous polyps to localize T-Ag expression in the adenomas using a monoclonal antibody, which was then confirmed by PCR and sequencing. Microsatellite instability analysis was also conducted in a pentaplex PCR and analyzed for deletion mutations. JCV T-Ag sequences were found in $82 \%$ (61 of 74) of adenomas, and T-Ag protein was expressed in 16\% (12 of 74) of these polyps. The T-Ag staining was localized exclusively within the nuclei of adenoma cells, but never in the cytoplasm or the adjacent non-neoplastic cells.

JCV T-Ag DNA sequences are frequently present in adenomatous polyps of the colon, and T-Ag is expressed specifically in the nuclei of these pre-malignant lesions, indicating that JCV T-antigen is present in the early stage of colonic carcinogenesis (74). JCV is identified in $26 \%$ of the patients using modified PCR reaction, to include topoisomerase, is used to decipher between cancer tissue and adjacent mucosa. Modification of the PCR reaction was showed to improve the ability to detect supercoiled viral DNA several fold. Increased percentage of detected viral DNA in CRC cells increased from $26 \%$ to $89 \%$ of the samples (both cases and controls) with this technical modification (68). In a study conducted on 23 carcinoma patients, 21 adenoma patients and 20 controls (75), JC virus was identified in $26 \%, 5 \%$ and $0 \%$, respectively. Theodoropulos et al. reported that $61 \%$ of 80 patients with carcinomas, $60 \%$ of 25 patients with adenomas, and $30 \%$ of controls were PCR positive for JC virus. More importantly, a viral load of $9 \times 10^{3}$ and $20 \times 10^{3}$ copies/ $\mu$ g DNA of adenocarcinomas and adenomas were detected, respectively. Adjacent normal mucosa in 35 positive colon adenocarcinoma specimens, and normal mucosa from six patients of the control group, had low viral loads 50-450 copies/ $\mu$ g DNA (76). Interestingly, PCR without adjustment with topoisomerase (77) showed statistically higher number of JCV copies in cancer than in non-cancerous tissues with a much higher relative number of copies/ $\mu \mathrm{g}$ of DNA (49.1 to $10.3 \times 10^{4}$ in cancer tissue compared to 9-20x $10^{3}$ in Theodoropoulos's study).

Similar to the S.bovis/galloliticus, there are researchers that propose only certain strains of JC virus are associated with CRC. This strain is Mad-1. In a study of 285 recombinant clones from the JCV TCR, 157 from non-neoplastic samples, and 128 from colon cancer tissues Mad-1 was responsible for the $98 \mathrm{bp}$ deletion exclusively in CRC, and it was never found in non-neoplastic cells (78).

\section{Human papillomavirus (HPV)}

Human papillomavirus (HPV) is the non-enveloped, double stranded DNA virus that infects the basal-layer of epithelial cells. There are a large number of HPV types with more than a dozen that are correlated with carcinogenesis (i.e. HPV type $16,18,31,33,35)$ and are classified as "high-risk" oncogenic infections. However, the carcinogenic potential of each strain varies. Of all the human papilloma viruses, HPV 16 and HPV 18 are considered to be the most carcinogenic with proven causal role in cancer development. These HPV types are strongly associated with cervical cancer; in one series, with more than $98.7 \%$ of all cervical cancer cases tested positive 
for HPV 16, 18 or both (79). A mechanism by which HPV causes cancer has been described. It involves viral early proteins E6 and E7 that were reported to interfere with tumor suppressor genes p53 and pRb. These proteins also interfere with telomerase and cause activation of cyclooxygenase 2 . Taken together, the effects of HPV infection lead to cell-cycle dysregulation, and finally to immortality of the cells. In vitro, E6-associateed protein has also been reported to interact with p53, increasing the ability of E6 to interfere with p53, and increasing degradation of p53, bringing even more variables in to the process of carcinogenesis (80); similarly E6-E7 fusion protein is involved in targeting $\mathrm{pRb}$ ubiquitination (81).

Due to nature of the virus, the majority of studies have used PCR and Southern blotting to detect the presence of HPV in the clinical samples. Other methods like ELISA and IHC were proven to be useful and sufficiently sensitive. An interesting study was conducted on DNA extracted from 109 formalin-fixed, paraffin-embedded tissue sections of colorectal adenomas and DNA was analyzed by PCR and Southern blot hybridization (82). In that study, also correlations of HPV types (HPV 6, 11, 16, 18, and 33) with histological adenomas adenoma sub-type were analyzed. Twenty-eight percent of all samples tested positive for presence of HPV DNA. Of 38 tubular adenomas, 40 tubulo-villous adenomas, 31 villous adenomas, 8, 13 and 10 were positive for the presence of viral DNA, respectively. All HPV-6 (11-positive cases) were tubular or tubulo-villous adenomas. Most HPV-16 infections (8/12) were seen in villous adenomas. Human papilloma virus-positive adenomas included three ( $8 \%$ ) of 38 that showed mild dysplasia, $10(25 \%)$ of 40 that showed moderate dysplasia, and $18(58 \%)$ of 31 that showed severe dysplasia. This is an important correlation between histological types of cancer with HPV-16. In addition, the association made between histological grade of epithelial dysplasia and HPV DNA is an important finding. In the colon, it has been reported that HPV can infect both normal, healthy mucosa and cancerous epithelial cells. This study was conducted on a small number of cases, 19 CRC patients, and the presence of viral DNA was confirmed both with PCR and Southern blotting (83).

A very informative clinical trial described below confirmed some of the previous laboratory findings. In order to investigate the association between HPV infection and CRC and gain more insight into mechanisms of carcinogenesis, 69 patients with pathologically confirmed primary CRC including 6 Stage I, 24 Stage II, 21 Stage III, and 18 Stage IV patients were enrolled into the study (84). Of the 69 colorectal tumors, HPV16 DNA was detected in $16 \%$ by nest-
ed-PCR, and HPV16 DNA was present in 73\% of tumors, which was confirmed by in situ hybridization. The presence of HPV16 DNA in colorectal tumors was not associated with patients' clinical parameters including age, gender, smoking status, tumor site; however, HPV16 infection was more common in earlier stage (Stage I) patients than in later stage patients (Stage II, III and IV). This study identified the presence of E6 oncogene in 73\% of HPV16 DNA-positive tumors and adjacent normal tissues including endothelial cells, lymphocytes, fibroblasts, and gland cells. Seventy-five percent of E6-positive tumors carried the p53 wild-type and had negative immunostaining for HPV16, but one tumor had less p53 immunostaining. Quantitative Real-Time Reverse Transcription PCR (qRT-PCR) analysis indicated that p21(regulator of cell cycle progression) and $\mathrm{mdm} 2$ (an important negative regulator of the p53 tumor suppressor) mRNA expression levels in E6/p53-wild-type tumors were significantly lower than in their adjacent normal tissues; as expected, E6-positive/p53-mutated tumors had lower p21 and mdm2 mRNA expression levels compared with their adjacent normal tissues, clearly indicating that the E6 oncoprotein expressed in p53 wild-type tumors may reduce $\mathrm{p} 21$ and $\mathrm{mdm} 2$ expression via p53 inactivation. The presence of the viral DNA in the normal mucosa implies that HPV is one of the factors correlated with CRC, however, these results have to be interpreted with caution since some reports show that infections with high-risk HPV is not sufficient to cause malignant transformation (85).

In a meta-analysis of nine case controlled-studies (86), researchers estimated Odds Ratio (OR) associated with HPV in CRC ranged from 2.7 to 9.1 (95\% $\mathrm{CI}=1.1-6.2$ and $95 \% \mathrm{CI}=3.7-22.3)$. The same authors conducted a case controlled study of individuals with colorectal adenomas $(n=167)$, hyperplastic polyps ( $\mathrm{n}$ $=87)$, and polyp-free controls $(n=250)$. Presence of HPV16 and HPV18 DNA and plasma antibodies for oncogenic HPV types were examined. Contrary to previous studies, HPV DNA was not found in any of the 609 successfully assayed colorectal tissue samples from adenomas, hyperplastic polyps, normal biopsies adjacent to polyps, or normal biopsies of the rectum of disease-free controls. Furthermore, no association was found between all oncogenic HPV types combined, for any polyp type, and for both genders. The only positive correlation between seropositivity and hyperplastic polyps when all oncogenic HPV types were combined $(\mathrm{OR}=3.0 ; 95 \% \mathrm{CI}$ : 1.1-7.9), was found when analyses were restricted to participants without a history of polyps, among men [adenomas $(n=31)$, hyperplastic polyps $(n=28)$, and controls $(n=68)$ ] (87). The authors concluded that there is insufficient 
evidence to support a correlation between CRC and the presence of HPV, and they recommended continuing research in this regard.

\section{Cytomegalovirus}

Human cytomegalovirus (HCMV) is carried by $50-80 \%$ of the population in the US. It is endemic in the human population worldwide and it can cause life-threatening disease in immunosuppressed adults. It has been shown in vitro to transform cells. Cobbs et al. used molecular biology and ICH methods to test hypothesis that HCMV is associated with CRC. They collected cancer tissues with adjacent normal cells from 29 patients. They found that $82 \%$ of colorectal polyps had IE1-72 protein and protein pp65 was evident in $78 \%$ of colorectal polyps. IE1-72 protein is shown to inhibit p53 action by preventing or disrupting p53 binding to p53-specific DNA sequences (88), and pp65 is integument protein involved in immune evasion (89). They showed slightly higher incidence, $92 \%$ of pp65 in adenocarcinomas, while IE1-72 had the same incidence of $80 \%$. None of the adjacent normal cells were positive for any of these two proteins (total nine patients). The same group showed in vitro that HCMV can induce genes that are contributing to cancer progression (Bcl-2 andCOX2). A larger study of163 CRC tissues and non-neoplastic adjacent tissues as controls were tested for the presence of HCMV (90). Results showed HCMV DNA (PCR), was detected in $42.3 \%(69 / 163)$ of the tumor specimens, while only $5.6 \%(14 / 163)$ of samples of adjacent non-neoplastic tissue were positive for HCMV ( $p<0.0001)$. Quantitative real-time PCR in 54 sample pairs revealed significantly higher viral copies in the tumor specimens than the adjacent non-neoplastic tissue specimens $(p<0.001)$. By ISH, the nucleic acids of HCMV were detected in the cytoplasm of neoplastic epithelium. No hybridization was detected in the inflammatory infiltrates, sub-mucosa, or other stromal tissues.

Similarly to opposite findings for the role of other infectious agents in the development of CRC, there are studies reporting contradictory results in case of HCMV. Akintola-Ogunremi et al. and Bender et al. reported negative findings. Twenty-three colorectal hyperplastic polyps, 65 colorectal adenomas, and 51 colorectal adenocarcinomas were examined by immunohistochemical analysis using two antibody mixtures that recognize CMV immediate-early, early, and delayed gene products (91). Negative results observed in ICH were confirmed with PCR. Another PCR-based study, specifically, nested PCR for HCMV, did not show significant correlation between presence of the virus and CRC. Only 5\% of adenomas and $21 \%$ of moderately differentiated adenocarcinoma were positive (92). No PCR positivity was obtained in samples from well and poorly differentiated adenocarcinomas. None of the authors however, excludesthe fact that the virus may present a "hit and run" like-mechanism and that HCMV can only be detectable at a particular stage of a progressing adenocarcinoma. They suggested that a significant number of CRCs might have been the subject of HCMV infection that could contribute to triggering events for oncogenic differentiation.

\section{Discussion}

CRC is a major problem in the medical field taking hundreds of thousands lives worldwide each year. It is the third most common cause of death amongst cancer patients. Carcinogenesis is a multi-step/multi-factorial process, which makes it difficult to epidemiologically evaluate or mimic precisely in a laboratory setting. It is known that only $3-5 \%$ of all CRCs are caused by hereditary factors, with the remainder of all CRC's being sporadic. Even though, epidemiological studies are difficult to conduct, some large population-based studies did identify high fat diet, Western civilization life style as risk factors. Associations between some bacterial and viral infections and CRC were made several decades ago. Infectious agents have been reported to be cause of a number of human cancers such as Merkel cell carcinoma, cervical cancer, Burkitt's lymphoma, Hodgkin lymphoma, and nasopharyngeal carcinoma. Those cancers are usually caused by small DNA viral infections with well described mechanistic data to support these findings.

Contrary to other cancers, the link between infectious agents and CRC has not been well described. This might be due to the mainstream opinion that was established a long time ago, that commensal bacteria have beneficial, symbiotic effects, as they are actively involved in the development and maturation of gut mucosa, prevention of infections with "bad" bacteria and in the degradation of metabolic byproducts. Over time, several observational and clinical studies indicated that bacteria and viruses may be an etiological link in the development of CRC. Early studies had their limitations, especially in prospective studies evaluating live fecal cultures in patients with CRC (i.e., these studies have been able to identify only living organisms, that are not attached to the tissue). With modern molecular biology techniques now available, we have new insights into bacterial and viral involvement in CRC. However, these studies have limitations as well. Sequencing of the microbiome is another approach that seems to be useful in identifying bacteria associated with $\mathrm{CRC}$, which will 
when coupled with clinical data provide a better understanding of so-called "good" and "bad" bacteria. This approach will eliminate the need for live bacterial culturing and provide a better understanding of bacterial flora within the colon and its possible link with CRC. Although it will be an immense challenge to sort out what data derived from a gut microbiome sequencing activity will really be actionable or meaningful in terms of drawing conclusions (vs. data noise). Another important point to consider in these future studies is a very stringent definition that infectious agents have to meet in order to be classified as cancerogenic. This definition states that to prove a causal relation between infection and cancer, given bacterium must be present in all cases, it must be isolated from the host and grown in pure culture, specific disease must be reproducible in a healthy susceptible host, and the bacterium must be experimentally recoverable from the host (93). This is clearly contradictory to the "hit and run" model for viral and the "driver-passenger" model for bacteria, which proposes a dynamic process involving infectious agents in cancerogenesis.

Decreasing the number of deaths from CRC relies in part on screening, early detection, removing polyps in the pre-malignant stage, and early treatment of the disease. Regular screening could decrease mortality by $60 \%$, yet less than $40 \%$ percent of CRC is detected early enough for curative treatment (94). When CRC is found and treated early, the five year survival rate is as high as 90 percent (95); unfortunately, only $40 \%$ of cases are identified at an early stage (96).

The U.S. active-duty military population may differ from the U.S. general population based on unique exposure to cancer-associated risk factors in the line of duty during out-of-country deployments. There are only a few studies that were conducted comparing cancer development between these two populations. One study (4) compared the incidence of four cancers common in U.S. adults (lung, colorectal, prostate, and breast cancers) and two cancers more common in U.S. young adults (testicular and cervical cancers) in the military and general populations. Data was obtained from the Automated Central Tumor Registry (ACTUR) of the Department of Defense and the nine cancer registries of the Surveillance, Epidemiology and End Results (SEER) of the National Cancer Institute between the years 1990 to 2004 for persons with ages 20 to 59 years. The authors reported significant differences in cancers incidence rates of several cancers between the civilian and active-duty military population. They reported lower incidence rates in the military population for colorectal cancer among Caucasian man compared to appropriately matched civilians, but only hypothesized about reasons for such finding. Authors suggested that these results could be due to generally more fit population, more stringent diets, lower obesity rates (weight requirements) and more frequent screenings since military members have free access to health care. Large, 2750 cases study was conducted in the U.S. Air Force active duty personnel (97). Authors standardized incidence ratios using US national incidence rates as reference for period 1998-2002. Colorectal cancer was reported to be seventh most common cancer in man and sixth most common cancer among women. Similar the conclusions of Zhu et al., Yamane concluded that there is significant difference amongst in cancer incidence rates between active duty Air Force personnel and civilians (97). However, according to 2009 Humana Military's Clinical Quality Report Card (http://www.humana-military.com/library/pdf/qm -report-card-2009.pdf) screening rates remain low, less than $60 \%$.

Service members particularly during deployment to foreign countries come into contact with various pathogens, and consequently develop infections. In one study conducted in Hungarian military service members (58) it's been reported that almost $30 \%$ of the young, H.pylori sero-negative, recruits(18-23 years old) convert to H.pylori sero-positive after completing either their 9-month or 6-month military service was 30\% (CI95\%: 25-35\%) and 23\% (CI95\%: 8-45\%), respectively. For example, during 7.5 months of deployment in Operation Desert Storm, close to 5\% of the deployed service members that were sero-negative for $H$. Pylori sero-converted with calculated $7.3 \%$ conversion rates over a one year period (57). Importantly, all seroconverted service members were young 20-25 years old and had acute infection as defined by sero-conversion, and appeared to be asymptomatic. One study reported $H$. pylori in $26 \%$ of US Army recruits and $25 \%$ of USN surface fleet personnel compared to $<10 \%$ of U.S. Navy submarine personnel (56). Even though it was considered that most of H.pylori infections occurred before adulthood (98), they reported that almost $2 \%$ sero-negative deployed service members converted to sero-positive during short $\sim 6$-month of deployment. Combined with the presented data, we hypothesize that young service members may become more susceptible to later gastrointestinal disease (IBD, Crohn's disease and $\mathrm{CRC}$ ).

We are outnumbered by our own microbiome and it is naive to underestimate the role of microorganisms present "in" and "on" our body and the risk of developing cancer. Clearly, more research is 
needed and warranted in order to better understand the association between infectious agents and human cancer development. This knowledge will lead to the development of improved and targeted therapeutics for human cancers and may save more lives amongst those afflicted by malignancy.

\section{Abbreviations}

CC: Colon Cancer

CRC: Colorectal Cancer

DNA: de-oxyribonucleic acid

mRNA: messenger Ribonucleic acid

PCR: Polymerase Chain Reaction

qRT-PCR:Quantitative Real-Time Reverse Transcription PCR (qRT-PCR)

ELISA: Enzyme Linked ImmunosorbentAssay

IHC: Immunohistochemistry

EBV: Epstein Barr virus

JCV: John Cunningham (JC) virus

HPV: Human Papilloma Virus

HCMV: Human Cytomegalo Virus

IE: infective endocarditis

PLA: pyogenic liver abscess

OR: Odds Ratio

\section{Contributing Author Declaration}

We certify that all individuals who qualify as authors have been listed; each has participated in one or more of the following areas: conception and design of this work, the acquisition and/or analysis of data, the writing, and/or critical revision of the document, and supervision of this cooperative research effort. All contributing authors approve of the submission of this version of the manuscript and assert that the document represents valid work. If information derived from another source was used in this manuscript, we obtained all necessary approvals to use it and made appropriate acknowledgements in the document. All contributing authors take public responsibility for this work.

Conception and design: Antonic, Stojadinovic, Weina, Izadjoo. Acquisition of data: Antonic, Stojadinovic. Analysis and interpretation of data: Antonic, Stojadinovic, Kester, Weina, Brücher, Avital, Izadjoo. Drafting of manuscript: Antonic, Stojadinovic, Izadjoo. Critical revision: Kester, Weina,Brücher, Avital. Supervision: Stojadinovic,Izadjoo, Avital.

\section{Disclaimer}

The views expressed in this manuscript are those of the authors and do not reflect the official policy of the Department of the Army, the Department of Defenseorthe United States Government or the Henry M Jackson Foundation for the Advancement of Military
Medicine.

\section{Copyright protection}

Some of the contributing authors are military service members (or employees of the U.S. Government: AS, KEK, PJW), and this work was prepared as part of their official duties. Title 17 U.S.C. 105 provides the "Copyright protection under this title is not available for any work of the United States Government." Title 17 U.S.C. 101 defines a U.S. Government work as a work prepared by a military service member or employee of the U.S. Government as part of that person's official duties.

\section{Acknowledgement}

This work was supported by the United States Military Cancer Institute (USMCI) and the Henry M. Jackson Foundation for the Advancement of Military Medicine.

\section{Competing Interests}

The authors have declared that no competing interest exists.

\section{References}

1. Knudson A. Alfred Knudson and his two-hit hypothesis. (Interview by Ezzie Hutchinson). Lancet Oncol. 2001;2(10):642-5.

2. Gastric cancer and Helicobacter pylori: a combined analysis of 12 case control studies nested within prospective cohorts. Gut. 2001;49(3):347-53.

3. Zhang B, Izadjoo M, Horkayne-Szakaly I, Morrison A, Wear DJ. Medulloblastoma and Brucellosis - Molecular Evidence of Brucella sp in Association with Central Nervous System Cancer. J Cancer. 2011;2:136-41.

4. Zhu K, Devesa SS, Wu H, Zahm SH, Jatoi I, Anderson WF, et al. Cancer incidence in the U.S. military population: comparison with rates from the SEER program. Cancer epidemiology, biomarkers \& prevention : a publication of the American Association for Cancer Research, cosponsored by the American Society of Preventive Oncology. 2009;18(6):1740-5

5. [Internet] CDC. Cancer - colorectal cancer screening rates. http://www.cdc.gov/cancer/colorectal/statistics/screening_rates.htm.

6. Tjalsma H, Boleij A, Marchesi JR, Dutilh BE. A bacterial driver-passenger model for colorectal cancer: beyond the usual suspects. Nature reviews Microbiology. 2012;10(8):575-82.

7. Kado S, Uchida K, Funabashi H, Iwata S, Nagata Y, Ando M, et al. Intestinal microflora are necessary for development of spontaneous adenocarcinoma of the large intestine in T-cell receptor beta chain and p53 double-knockout mice. Cancer research. 2001;61(6):2395-8.

8. Balish E, Warner T. Enterococcus faecalis induces inflammatory bowel disease in interleukin-10 knockout mice. The American journal of pathology. 2002;160(6):2253-7.

9. Chu FF, Esworthy RS, Chu PG, Longmate JA, Huycke MM, Wilczynski $\mathrm{S}$, et al. Bacteria-induced intestinal cancer in mice with disrupted Gpx1 and Gpx2 genes. Cancer research. 2004;64(3):962-8.

10. Rudolph U, Bradley A, Birnbaumer L. Targeted inactivation of the Gi2 alpha gene with replacement and insertion vectors: analysis in a 96-well plate format. Methods in enzymology. 1994;237:366-86.

11. Zhu Y, Richardson JA, Parada LF, Graff JM. Smad3 mutant mice develop metastatic colorectal cancer. Cell. 1998;94(6):703-14

12. Velcich A, Yang W, Heyer J, Fragale A, Nicholas C, Viani S, et al. Colorectal cancer in mice genetically deficient in the mucin Muc2. Science. 2002;295(5560):1726-9.

13. Engle SJ, Hoying JB, Boivin GP, Ormsby I, Gartside PS, Doetschman T. Transforming growth factor beta1 suppresses nonmetastatic colon 
cancer at an early stage of tumorigenesis. Cancer research. 1999;59(14):3379-86.

14. Shah SA, Simpson SJ, Brown LF, Comiskey M, de Jong YP, Allen D, et al. Development of colonic adenocarcinomas in a mouse model of ulcerative colitis. Inflammatory bowel diseases. 1998;4(3):196-202.

15. Mangerich A, Knutson CG, Parry NM, Muthupalani S, Ye W, Prestwich $\mathrm{E}$, et al. Infection-induced colitis in mice causes dynamic and tissue-specific changes in stress response and DNA damage leading to colon cancer. Proc Natl Acad Sci U S A. 2012;109(27):E1820-9.

16. Wang T, Cai G, Qiu Y, Fei N, Zhang M, Pang X, et al. Structural segregation of gut microbiota between colorectal cancer patients and healthy volunteers. The ISME journal. 2012;6(2):320-9. .

17. Roses DF, Richman H, Localio SA. Bacterial endocarditis associated with colorectal carcinoma. Annals of surgery. 1974;179(2):190-1.

18. Osawa R, Sasaki E. Novel observations of genotypic and metabolic characteristics of three subspecies of Streptococcus gallolyticus. Journal of clinical microbiology. 2004;42(10):4912-3.

19. Gupta A, Madani R, Mukhtar H. Streptococcus bovis endocarditis, a silent sign for colonic tumour. Colorectal disease : the official journal of the Association of Coloproctology of Great Britain and Ireland. 2010;12(3):164-71

20. Corredoira J, Alonso MP, Coira A, Casariego E, Arias C, Alonso D, et al. Characteristics of Streptococcus bovis endocarditis and its differences with Streptococcus viridans endocarditis. European journal of clinical microbiology \& infectious diseases : official publication of the European Society of Clinical Microbiology. 2008;27(4):285-91.

21. Corredoira J, Alonso MP, Pita J, Alonso-Mesonero D. Association between rural residency, group D streptococcal endocarditis and colon cancer? Clinical microbiology and infection : the official publication of the European Society of Clinical Microbiology and Infectious Diseases. 2008;14(2):190.

22. Kok H, Jureen R, Soon CY, Tey BH. Colon cancer presenting as Streptococcus gallolyticus infective endocarditis. Singapore medical journal. 2007;48(2):e43-5.

23. Zarkin BA, Lillemoe KD, Cameron JL, Effron PN, Magnuson TH, Pitt HA. The triad of Streptococcus bovis bacteremia, colonic pathology, and liver disease. Annals of surgery. 1990;211(6):786-91.

24. Alazmi W, Bustamante M, O'Loughlin C, Gonzalez J, Raskin JB. The association of Streptococcus bovis bacteremia and gastrointestinal diseases: a retrospective analysis. Digestive diseases and sciences. 2006;51(4):732-6.

25. Darjee R, Gibb AP. Serological investigation into the association between Streptococcus bovis and colonic cancer. Journal of clinical pathology. 1993;46(12):1116-9.

26. Klein RS, Recco RA, Catalano MT, Edberg SC, Casey JI, Steigbigel NH. Association of Streptococcus bovis with carcinoma of the colon. The New England journal of medicine. 1977;297(15):800-2.

27. Dubrow R, Edberg S, Wikfors E, Callan D, Troncale F, Vender R, et al. Fecal carriage of Streptococcus bovis and colorectal adenomas. Gastroenterology. 1991;101(3):721-5.

28. Norfleet RG, Mitchell PD. Streptococcus bovis does not selectively colonize colorectal cancer and polyps. Journal of clinical gastroenterology. 1993;17(1):25-8.

29. Burns CA, McCaughey R, Lauter CB. The association of Streptococcus bovis fecal carriage and colon neoplasia: possible relationship with polyps and their premalignant potential. The American journal of gastroenterology. 1985;80(1):42-6.

30. Abdulamir AS, Hafidh RR, Bakar FA. Molecular detection, quantification, and isolation of Streptococcus gallolyticus bacteria colonizing colorectal tumors: inflammation-driven potential of carcinogenesis via IL-1, COX-2, and IL-8. Molecular cancer. 2010;9:249.

31. Abdulamir AS, Hafidh RR, Mahdi LK, Al-jeboori T, Abubaker F. Investigation into the controversial association of Streptococcus gallolyticus with colorectal cancer and adenoma. BMC cancer. 2009;9:403.

32. Boleij A, Roelofs R, Danne C, Bellais S, Dramsi S, Kato I, et al. Selective antibody response to Streptococcus gallolyticus pilus proteins in colorectal cancer patients. Cancer Prev Res (Phila). 2012;5(2):260-5.

33. Corredoira-Sanchez J, Garcia-Garrote F, Rabunal R, Lopez-Roses L, Garcia-Pais MJ, Castro E, et al. Association Between Bacteremia Due to Streptococcus gallolyticus subsp. gallolyticus (Streptococcus bovis I) and Colorectal Neoplasia: A Case-Control Study. Clinical infectious diseases : an official publication of the Infectious Diseases Society of America. 2012;55(4):491-6.

34. Boleij A, Dutilh BE, Kortman G, Roelofs R, Laarakkers CM, Engelke UF, et al. Bacterial responses to a simulated colon tumor microenvironment. Molecular \& cellular proteomics : MCP. 2012.
35. Boleij A, Muytjens CM, Bukhari SI, Cayet N, Glaser P, Hermans PW, et al. Novel clues on the specific association of Streptococcus gallolyticus subsp gallolyticus with colorectal cancer. The Journal of infectious diseases. 2011;203(8):1101-9.

36. Schistosomes, liver flukes and Helicobacter pylori. IARC Working Group on the Evaluation of Carcinogenic Risks to Humans. Lyon, 7-14 June 1994. IARC monographs on the evaluation of carcinogenic risks to humans / World Health Organization, International Agency for Research on Cancer. 1994;61:1-241.

37. Di Napoli A, Petrino R, Boero M, Bellis D, Chiandussi L. Quantitative assessment of histological changes in chronic gastritis after eradication of Helicobacter pylori. Journal of clinical pathology. 1992;45(9):796-8.

38. Ahmed N. Coevolution and adaptation of Helicobacter pylori and the case for 'functional molecular infection epidemiology'. Medical principles and practice : international journal of the Kuwait University, Health Science Centre. 2011;20(6):497-503.

39. Crespo A, Suh B. Helicobacter pylori infection: epidemiology, pathophysiology, and therapy. Archives of pharmacal research. 2001;24(6):485-98

40. Taylor DN, Blaser MJ. The epidemiology of Helicobacter pylori infection. Epidemiologic reviews. 1991;13:42-59.

41. Strofilas A, Lagoudianakis EE, Seretis C, Pappas A, Koronakis N, Keramidaris D, et al. Association of helicobacter pylori infection and colon cancer. Journal of clinical medicine research. 2012;4(3):172-6.

42. Shmuely H, Passaro D, Figer A, Niv Y, Pitlik S, Samra Z, et al. Relationship between Helicobacter pylori CagA status and colorectal cancer. The American journal of gastroenterology. 2001;96(12):3406-10.

43. Hartwich A, Konturek SJ, Pierzchalski P, Zuchowicz M, Labza H, Konturek PC, et al. Helicobacter pylori infection, gastrin, cyclooxygenase-2, and apoptosis in colorectal cancer. International journal of colorectal disease. 2001;16(4):202-10.

44. Penman ID, el-Omar E, Ardill JE, McGregor JR, Galloway DJ, O'Dwyer $\mathrm{PJ}$, et al. Plasma gastrin concentrations are normal in patients with colorectal neoplasia and unaltered following tumor resection. Gastroenterology. 1994;106(5):1263-70.

45. Moss SF, Neugut AI, Garbowski GC, Wang S, Treat MR, Forde KA. Helicobacter pylori seroprevalence and colorectal neoplasia: evidence against an association. Journal of the National Cancer Institute. 1995;87(10):762-3.

46. Meucci G, Tatarella M, Vecchi M, Ranzi ML, Biguzzi E, Beccari G, et al. High prevalence of Helicobacter pylori infection in patients with colonic adenomas and carcinomas. Journal of clinical gastroenterology. 1997;25(4):605-7.

47. Fireman Z, Trost L, Kopelman Y, Segal A, Sternberg A. Helicobacter pylori: seroprevalence and colorectal cancer. Isr Med Assoc J. 2000;2(1):6-9.

48. Hong SN, Lee SM, Kim JH, Lee TY, Choe WH, Lee SY, et al. Helicobacter pylori infection increases the risk of colorectal adenomas: cross-sectional study and meta-analysis. Digestive diseases and sciences. 2012;57(8):2184-94.

49. Zhang $Y$, Hoffmeister M, Weck MN, Chang-Claude J, Brenner $\mathrm{H}$. Helicobacter pylori infection and colorectal cancer risk: evidence from a large population-based case-control study in Germany. American journal of epidemiology. 2012;175(5):441-50.

50. Zumkeller N, Brenner H, Chang-Claude J, Hoffmeister M, Nieters A, Rothenbacher D. Helicobacter pylori infection, interleukin-1 gene polymorphisms and the risk of colorectal cancer: evidence from a case-control study in Germany. Eur J Cancer. 2007;43(8):1283-9.

51. Limburg PJ, Stolzenberg-Solomon RZ, Colbert LH, Perez-Perez GI, Blaser MJ, Taylor PR, et al. Helicobacter pylori seropositivity and colorectal cancer risk: a prospective study of male smokers. Cancer epidemiology, biomarkers \& prevention : a publication of the American Association for Cancer Research, cosponsored by the American Society of Preventive Oncology. 2002;11(10 Pt 1):1095-9.

52. Robertson DJ, Sandler RS, Ahnen DJ, Greenberg ER, Mott LA, Cole BF, et al. Gastrin, Helicobacter pylori, and colorectal adenomas. Clin Gastroenterol Hepatol. 2009;7(2):163-7.

53. Zumkeller N, Brenner H, Zwahlen M, Rothenbacher D. Helicobacter pylori infection and colorectal cancer risk: a meta-analysis. Helicobacter. 2006;11(2):75-80.

54. Zhao YS, Wang F, Chang D, Han B, You DY. Meta-analysis of different test indicators: Helicobacter pylori infection and the risk of colorectal cancer. International journal of colorectal disease. 2008;23(9):875-82.

55. Zhang Y, Gao C, Zhai JH. [Meta-analysis on the relationship between colorectal cancer and Helicobacter pylori infection]. Zhonghua Liu Xing Bing Xue Za Zhi. 2009;30(1):73-7. 
56. Jackman RP, Schlichting C, Carr W, Dubois A. Prevalence of Helicobacter pylori in United States Navy submarine crews. Epidemiology and infection. 2006;134(3):460-4. PMCID: 2576507.

57. Taylor DN, Sanchez JL, Smoak BL, DeFraites R. Helicobacter pylori infection in Desert Storm troops. Clinical infectious diseases : an official publication of the Infectious Diseases Society of America. 1997;25(5):979-82.

58. Furesz J, Lakatos S, Nemeth K, Fritz P, Simon L, Kacserka K. The prevalence and incidence of Helicobacter pylori infections among young recruits during service in the Hungarian Army. Helicobacter. 2004;9(1):77-80.

59. Guo Y, Cen Z, Zou Y, Fang X, Li T, Wang J, et al. Whole-genome sequence of Klebsiella pneumonia strain LCT-KP214. Journal of bacteriology. 2012;194(12):3281. PMCID: 3370881.

60. Lederman ER, Crum NF. Pyogenic liver abscess with a focus on Klebsiella pneumoniae as a primary pathogen: an emerging disease with unique clinical characteristics. The American journal of gastroenterology. 2005;100(2):322-31.

61. Qu K, Liu C, Wang ZX, Tian F, Wei JC, Tai MH, et al. Pyogenic liver abscesses associated with nonmetastatic colorectal cancers: an increasing problem in Eastern Asia. World journal of gastroenterology : WJG. 2012;18(23):2948-55. PMCID: 3380322.

62. Jeong SW, Jang JY, Lee TH, Kim HG, Hong SW, Park SH, et al. Cryptogenic pyogenic liver abscess as the herald of colon cancer. Journal of gastroenterology and hepatology. 2012;27(2):248-55.

63. Huang WK, Chang JW, See LC, Tu HT, Chen JS, Liaw CC, et al. Higher rate of colorectal cancer among patients with pyogenic liver abscess with Klebsiella pneumoniae than those without: an 11-year follow-up study. Colorectal disease : the official journal of the Association of Coloproctology of Great Britain and Ireland. 2012.

64. Kostic AD, Gevers D, Pedamallu CS, Michaud M, Duke F, Earl AM, et al. Genomic analysis identifies association of Fusobacterium with colorectal carcinoma. Genome research. 2012;22(2):292-8. PMCID: 3266036.

65. Castellarin M, Warren RL, Freeman JD, Dreolini L, Krzywinski M, Strauss J, et al. Fusobacterium nucleatum infection is prevalent in human colorectal carcinoma. Genome research. 2012;22(2):299-306. PMCID: 3266037.

66. Saha A, Kaul R, Murakami M, Robertson ES. Tumor viruses and cancer biology: Modulating signaling pathways for therapeutic intervention. Cancer biology \& therapy. 2010;10(10):961-78

67. Bergonzini V, Salata C, Calistri A, Parolin C, Palu G. View and review on viral oncology research. Infectious agents and cancer. 2010;5:11. PMCID: 2881002.

68. Laghi L, Randolph AE, Chauhan DP, Marra G, Major EO, Neel JV, et al. JC virus DNA is present in the mucosa of the human colon and in colorectal cancers. Proceedings of the National Academy of Sciences of the United States of America. 1999;96(13):7484-9. PMCID: 22112.

69. Casini B, Borgese L, Del Nonno F, Galati G, Izzo L, Caputo M, et al. Presence and incidence of DNA sequences of human polyomaviruses $\mathrm{BKV}$ and JCV in colorectal tumor tissues. Anticancer research. 2005;25(2A):1079-85.

70. Enam S, Del Valle L, Lara C, Gan DD, Ortiz-Hidalgo C, Palazzo JP, et al. Association of human polyomavirus JCV with colon cancer: evidence for interaction of viral T-antigen and beta-catenin. Cancer research. 2002;62(23):7093-101.

71. Goel A, Li MS, Nagasaka T, Shin SK, Fuerst F, Ricciardiello L, et al. Association of JC virus T-antigen expression with the methylator phenotype in sporadic colorectal cancers. Gastroenterology. 2006;130(7):1950-61.

72. Lin PY, Fung CY, Chang FP, Huang WS, Chen WC, Wang JY, et al. Prevalence and genotype identification of human JC virus in colon cancer in Taiwan. Journal of medical virology. 2008;80(10):1828-34.

73. Ricciardiello L, Laghi L, Ramamirtham P, Chang CL, Chang DK, Randolph AE, et al. JC virus DNA sequences are frequently present in the human upper and lower gastrointestinal tract. Gastroenterology. 2000;119(5):1228-35.

74. Jung WT, Li MS, Goel A, Boland CR. JC virus T-antigen expression in sporadic adenomatous polyps of the colon. Cancer. 2008;112(5):1028-36. PMCID: 2855201.

75. Hori R, Murai Y, Tsuneyama K, Abdel-Aziz HO, Nomoto K, Takahashi $\mathrm{H}$, et al. Detection of JC virus DNA sequences in colorectal cancers in Japan. Virchows Archiv : an international journal of pathology. 2005;447(4):723-30.

76. Theodoropoulos G, Panoussopoulos D, Papaconstantinou I, Gazouli M, Perdiki M, Bramis J, et al. Assessment of JC polyoma virus in colon neoplasms. Diseases of the colon and rectum. 2005;48(1):86-91.
77. Mou X, Chen L, Liu F, Lin J, Diao P, Wang H, et al. Prevalence of JC virus in Chinese patients with colorectal cancer. PloS one. 2012;7(5):e35900. PMCID: 3350510

78. Ricciardiello L, Chang DK, Laghi L, Goel A, Chang CL, Boland CR. Mad-1 is the exclusive JC virus strain present in the human colon, and its transcriptional control region has a deleted 98-base-pair sequence in colon cancer tissues. Journal of virology. 2001;75(4):1996-2001. PMCID: 115147.

79. Kado S, Kawamata Y, Shino Y, Kasai T, Kubota K, Iwasaki H, et al. Detection of human papillomaviruses in cervical neoplasias using multiple sets of generic polymerase chain reaction primers. Gynecologic oncology. 2001;81(1):47-52.

80. Huibregtse JM, Scheffner M, Howley PM. Cloning and expression of the cDNA for E6-AP, a protein that mediates the interaction of the human papillomavirus E6 oncoprotein with p53. Molecular and cellular biology. 1993;13(2):775-84. PMCID: 358960.

81. Scheffner M, Munger K, Huibregtse JM, Howley PM. Targeted degradation of the retinoblastoma protein by human papillomavirus E7-E6 fusion proteins. The EMBO journal. 1992;11(7):2425-31. PMCID: 556717.

82. Cheng JY, Sheu LF, Lin JC, Meng CL. Detection of human papillomavirus DNA in colorectal adenomas. Arch Surg. 1995;130(1):73-6.

83. Lee YM, Leu SY, Chiang H, Fung CP, Liu WT. Human papillomavirus type 18 in colorectal cancer. Journal of microbiology, immunology, and infection = Wei mian yu gan ran za zhi. 2001;34(2):87-91.

84. Chen TH, Huang CC, Yeh KT, Chang SH, Chang SW, Sung WW, et al. Human papilloma virus 16 E6 oncoprotein associated with p53 inactivation in colorectal cancer. World journal of gastroenterology : WJG. 2012;18(30):4051-8. PMCID: 3420003.

85. Steenbergen RD, de Wilde J, Wilting SM, Brink AA, Snijders PJ, Meijer CJ. HPV-mediated transformation of the anogenital tract. Journal of clinical virology : the official publication of the Pan American Society for Clinical Virology. 2005;32 Suppl 1:S25-33.

86. Burnett-Hartman AN, Newcomb PA, Potter JD. Infectious agents and colorectal cancer: a review of Helicobacter pylori, Streptococcus bovis, JC virus, and human papillomavirus. Cancer epidemiology, biomarkers \& prevention : a publication of the American Association for Cancer Research, cosponsored by the American Society of Preventive Oncology. 2008;17(11):2970-9. PMCID: 2676114.

87. Burnett-Hartman AN, Newcomb PA, Mandelson MT, Galloway DA, Madeleine MM, Wurscher MA, et al. No evidence for human papillomavirus in the etiology of colorectal polyps. Cancer epidemiology, biomarkers \& prevention : a publication of the American Association for Cancer Research, cosponsored by the American Society of Preventive Oncology. 2011;20(10):2288-97. PMCID: 3236024.

88. Hwang ES, Zhang Z, Cai H, Huang DY, Huong SM, Cha CY, et al. Human cytomegalovirus IE1-72 protein interacts with p53 and inhibits p53-dependent transactivation by a mechanism different from that of IE2-86 protein. Journal of virology. 2009;83(23):12388-98. PMCID: 2786713.

89. Tomtishen JP, 3rd. Human cytomegalovirus tegument proteins (pp65, pp71, pp150, pp28). Virology journal. 2012;9:22. PMCID: 3278345.

90. Chen HP, Jiang JK, Chen CY, Chou TY, Chen YC, Chang YT, et al. Human cytomegalovirus preferentially infects the neoplastic epithelium of colorectal cancer: a quantitative and histological analysis. Journal of clinical virology : the official publication of the Pan American Society for Clinical Virology. 2012;54(3):240-4.

91. Akintola-Ogunremi O, Luo $\mathrm{Q}, \mathrm{He}$ TC, Wang HL. Is cytomegalovirus associated with human colorectal tumorigenesis? American journal of clinical pathology. 2005;123(2):244-9.

92. Bender C, Zipeto D, Bidoia C, Costantini S, Zamo A, Menestrina F, et al. Analysis of colorectal cancers for human cytomegalovirus presence. Infectious agents and cancer. 2009;4:6. PMCID: 2674415.

93. Evans AS. Causation and disease: the Henle-Koch postulates revisited. The Yale journal of biology and medicine. 1976;49(2):175-95. PMCID: 2595276.

94. Zittleman L, Emsermann C, Dickinson M, Norman N, Winkelman K, Linn $G$, et al. Increasing colon cancer testing in rural Colorado: evaluation of the exposure to a community-based awareness campaign. BMC Public Health. 2009;9:288. PMCID: 2731102.

95. Levin B, Lieberman DA, McFarland B, Smith RA, Brooks D, Andrews $\mathrm{KS}$, et al. Screening and surveillance for the early detection of colorectal cancer and adenomatous polyps, 2008: a joint guideline from the American Cancer Society, the US Multi-Society Task Force on Colorectal Cancer, and the American College of Radiology. CA Cancer J Clin. 2008;58(3):130-60. 
96. [Internet] AmericanCancerSociety. Cancer prevention \& early detection facts \& figures 2008. http://www.cancer.org/research/ cancerfactsfigures/cancer-prevention-early-detection-facts-figures-2008.

97. Yamane GK. Cancer incidence in the U.S. Air Force: 1989-2002. Aviat Space Environ Med. 2006;77(8):789-94.

98. Hyams KC, Taylor DN, Gray GC, Knowles JB, Hawkins R, Malone JD. The risk of Helicobacter pylori infection among U.S. military personnel deployed outside the United States. The American journal of tropical medicine and hygiene. 1995;52(1):109-12. 